\title{
Productivity of Dairy Supply Chains: A Comparative Analysis Across the Countries of the Baltic Sea Region
}

\author{
Xavier Irz $^{1)}$ \& Natalia Kuosmanen ${ }^{2)}$
}

1) MTT Agrifood Research Finland, Economic Research Unit, Latokartanonkaari 9, 00790 Helsinki; e-mail: xavier.irz@mtt.fi

2) MTT Agrifood Research Finland, Economic Research Unit, Latokartanonkaari 9, 00790 Helsinki; e-mail: nataliya.kuosmanen@mtt.fi

\begin{abstract}
To explore the competitiveness of the Finnish dairy chain, we analysed its productivity performance relative to that of other Baltic countries: Sweden, Denmark, Germany, Poland, and the three Baltic states. We used partial productivity indicators and indices of total factor productivity (TFP) to investigate productivity growth and productivity levels in both dairy farming and dairy manufacturing, using data from the Farm Accountancy Data Network as well as national industrial statistics.
\end{abstract}

At farm level, there are enormous differences in the level of labour productivity across the eight countries: a dairy farmer in Denmark produces 13 times more milk than one in Latvia or Lithuania. Labour productivity in Finland is also significantly lower than in the other old EU countries - not only Denmark, the clear leader, but also Germany and Sweden. Further, there is evidence that Estonia is catching up with Finland in terms of labour productivity. A decomposition analysis then shows that the cross-country differences in labour productivity on farms are driven primarily by differences in labour requirements per cow, while differences in milk yields account for a much smaller share of the difference. Thus, the key to high labour productivity in dairy is the farm structure and the adoption of mechanical innovations, while differences in adoption of biological innovations (e.g., genetic improvement, feeds) are relatively less important.

In a second step, a growth accounting exercise indicates that growth in farm-level production in the four older EU members has occurred through different channels, but that TFP growth rates have been roughly comparable from 1995 to 2010. Thus, the competitive position of Finnish dairy farms relative to those in Sweden, Germany and Denmark has not changed greatly over the last two decades. More positively, we find that in recent years (i.e., since 2004), TFP on Finnish farms has grown much faster than on German and Swedish farms. Altogether, Finnish farms appear in the process of raising their productivity to the level achieved by German and Swedish farms, while Danish farms are probably out of reach. Extending the comparison to include the new EU members reveals that dairy farms in those countries are lagging behind Finnish ones in terms of productivity and are not catching up. Although Estonian farms, which are on average relatively large, have recorded impressive increases in yields and labour productivity, this has been achieved more by substitutions of other production factors for labour than real efficiency gains.

The processing level of the Finnish dairy supply chain appears more competitive when benchmarked against the processing sectors of the old EU members, although TFP growth has been slow in absolute terms. However, the productivity of dairy manufacturing in Poland and Lithuania is increasing rapidly and converging towards the levels observed in the older EU countries. Overall, the evolution documented in the paper is consistent with the view that transferring technologies and organisational forms from the productivity leaders to the productivity "laggards" is easier in the manufacturing sector than in primary production, due to the typical difference in the size of firms as well as the more pronounced reliance of the primary sector on country-specific agro-ecological conditions.

Key words: TFP; Productivity; Dairy; Milk; Farm; Competitiveness 


\section{Introduction}

The dairy supply chain remains the cornerstone of the Finnish agri-food sector because of its quantitative importance and the suitability of milk farming to the agro-ecological conditions of the country. In terms of primary production, dairy farming accounted for 36 percent of the value of agricultural production in year 2012 (Niemi \& Ahlstedt 2013), or approximately twice the share of the crop sector. Further, analyses of futures have revealed that the dairy sector forms one of the main building blocks of an ideal agricultural sector in Finland, or what Rikkonen (2005) refers to as "daydream agriculture". Even at retail level, the dairy sector remains quantitatively significant, with Finnish consumers allocating almost a quarter of their food budget to this product group (Irz \& Kuosmanen, 2013). Yet the sector is facing important challenges: the Common Agriculture Policy (CAP) reform initiated in 2008 requires the removal of the milk quota system by 2015 , which, together with the gradual decoupling of farm subsidies, implies an increasing exposure of Finnish milk farmers to market forces (Lelyon et al. 2011). Meanwhile, food retailers are becoming increasingly concentrated and powerful, with imports of dairy products becoming more common and intensifying competition from other EU countries.

Against this background, ensuring the competitiveness of the dairy sector in Finland appears essential to the economic vitality of Finnish rural areas and the sustainability of the Finnish agricultural sector. In pursuit of that goal, a recently completed project funded by the Ministry of Agriculture and Forestry monitored the competitiveness of the Finnish dairy supply chain against similar chains in the seven other EU countries of the Baltic Sea region (namely Denmark, Germany, Sweden, Poland, and the three Baltic states) and, through detailed case studies, identified the factors explaining the relative competitiveness of those countries.

Although several definitions of competitiveness are available in the literature, we consider here that the competitiveness of an industry such as the dairy sector is achieved when individual companies within that industry are able to sell goods or services at a price and quality that compare favourably to those of competitors. Two important ideas, stressed in the conclusion of a review paper on the competitiveness in the Agri-Food sector commissioned by the OECD (Latruffe, 2010), follow. First, competitiveness is a relative concept and should be measured with respect to a benchmark. Here, the other seven countries, which account for most of the trade in dairy products in the region, often have the same multi-national dairy processors, and share some natural conditions (climate), form a natural benchmark for Finland. Second, in spite of the simple definition, competitiveness is a complex concept that incorporates a multitude of aspects, which vary in the ease with which they can be measured. Although productivity figures prominently among the list of potential competitiveness indicators (Aiginger, 2006; DEFRA, 2002), one should interpret the results in our paper as only one part of a more complex picture, as described in the full project report.

\section{Material and Methods}

The productivity of a firm or sector is simply defined as the ratio of outputs to inputs (Coelli et al., 1998, p. 2). While the value of a productivity index is meaningless by itself, changes over time (i.e., productivity growth) and differences across units are informative about competitiveness positions and their evolution. If the production process involved a single input and a single output, calculating productivity levels would be straightforward, but this is unfortunately never the case in reality, so that the problem of measuring productivity becomes one of aggregating inputs and outputs into appropriate indices. Partial productivity measures simplify the aggregation problem by typically focusing on only one input/output (e.g., milk for outputs, labour, dairy cows or land for inputs). The main advantage is the ease of calculation and interpretation, and we therefore calculate selfexplanatory measures of milk yield (e g., milk output per dairy cow) and labour productivity in what follows. However, at the farm level, the selection of specific indicators is guided by the literature on technical change and development in agriculture initiated by Hayami \& Ruttan (1991). Specifically, labour productivity $(\mathrm{Y} / \mathrm{L})$ is partitioned into output per dairy cow $(\mathrm{Y} / \mathrm{C})$ and the number of dairy cows per worker $(\mathrm{C} / \mathrm{L})$ according to the relationship: $\mathrm{Y} / \mathrm{L}=\mathrm{Y} / \mathrm{C} * \mathrm{C} / \mathrm{L}$. This decomposition breaks down labour productivity into two conceptually distinct parts: an increase in output per dairy cow (i.e., yield) reflects mainly biological innovations, such as genetic improvements or the amelioration of 
feed composition. On the other hand, the number of dairy cows per worker changes mainly with mechanical innovations, such as the labour requirement of milking machines or automation of other production processes such as feeding, cleaning, maintenance etc.

Partial productivity measures, however, do not make it possible to separate real efficiency gains from substitutions among inputs - for instance, high milk yields are not necessarily desirable if achieved through an inefficient use of costly feeds. Total Factor Productivity (TFP) measures, which integrate all inputs and all outputs in the calculation, have therefore been developed and we report the Tornqvist index because of its superior economic properties (Coelli et al., 1998).

The analysis of productivity of dairy farms relies on the aggregate data provided by the European Commission's Public Database of the Farm Accountancy Data Network (FADN) ${ }^{1}$ for "Specialist milk farm" from 1995 to 2010 (and from 2005 onwards for the four relatively new EU members). The data records the values of three outputs, including milk, which are deflated using the corresponding price indices in the EUROSTAT database ${ }^{2}$. Input values are recorded for the main variable production factors, namely fertilisers, commercial feeds, pesticides, energy and seeds. The cost of family labour is imputed, and the cost of four classes of capital goods (land, buildings, machinery and livestock) is calculated as the sum of depreciation costs and opportunity cost of the investments, using as interest rate the yield on long-run government bonds, as given by the European Central Bank database ${ }^{3}$.

For dairy processing, EUROSTAT's Structural Business Statistics provided data on gross output, value added at factor cost and total number of employees, which were combined to producer price indices (PPIs) from the short-term business statistics to calculate labour productivity. In order to calculate a TFP index, substantial effort had to be devoted to retrieving the data directly from National Statistical Institutes.

\section{Results and discussion}

Table 1 presents the partial productivity measures at farm level and reveals tremendous variations across countries. In year 2010, one hour of labour on a dairy farm produced on average $255 \mathrm{~kg}$ of milk in Denmark but only $58 \mathrm{~kg}$ in Finland and $15 \mathrm{~kg}$ in Latvia - a variation of a factor 17. On the basis of that indicator, Finnish dairy farms are not very competitive, lagging behind those in Denmark, Sweden and Germany. The new entrants have much lower levels of labour productivity than Finland, although Estonian farms outperform Latvian, Lithuanian, and Polish farms by a large margin. Looking at changes over time, labour productivity has grown very rapidly in all countries, and among the old EU members Finland performs well in terms of that indicator, although differences in growth rates are not enough to significantly change the competitive positions of the old EU members: Denmark is the clear leader throughout the period, Sweden and Germany have rather similar levels of productivity, while Finland lags behind. Turning to the situation of the new entrants, Estonia stands out by its large growth rate of labour productivity ( $+13 \%$ annually), which is significantly larger than the Finnish rate over the 2004-2010 period, and the labour productivity gap between Finnish and Estonian farms has therefore decreased. By contrast, there is no evidence of the other three new entrants catching up in terms of labour productivity, with Polish farms displaying particularly small rates of growth.

Focusing on the first component of labour productivity, milk yields vary across countries, but three broad groups of countries can be established at the end of the period: 1- the yield leaders include Finland, Denmark and Sweden. For those countries, a dairy cow produces on average roughly 8500 $\mathrm{kg}$ of milk; 2- Germany and Estonia form an intermediate group of countries, with yields around 7500 kg per dairy cow; 3- The "laggard" countries (Latvia, Lithuania and Poland) display yields around $5000 \mathrm{~kg}$ per dairy cow. Yields are clearly increasing over time but the speed of the growth is limited,

\footnotetext{
${ }^{1}$ Available online at: http://ec.europa.eu/agriculture/rica/index.cfm.

${ }^{2}$ http://epp.eurostat.ec.europa.eu/portal/page/portal/agriculture/data/database, categories Agricultural prices and prices indices - Price indices of agricultural products $(2005=100)$.

${ }^{3} \mathrm{http}: / / \mathrm{sdw}$. ecb.europa.eu/browse.do?node=bbn3146
} 
usually under $2 \%$ annually, with the exception of Estonia, which managed to close its yield gap with Germany after joining the EU. From 1995 to 2010, the Finnish, Danish, and Swedish yields converged and the calculations suggest that growth in yields beyond $8000 \mathrm{~kg}$ is becoming increasingly difficult.

Differences in the number of hours of labour per dairy cow are much more important than yields in explaining differences in labour productivity levels across countries. In 2010, a Lithuanian dairy cow required on average ten times more labour than a Danish cow, and it is clearly in that dimension that Finnish farms are performing poorly compared to their competitors, with a requirement of 148 hours per dairy cow in 2010. This is more than four times the corresponding figure for Danish cows, and nearly twice the labour requirements for German and Swedish cows.

Average TFP growth on dairy farms is then compared among the old EU member states from 1995 to 2010 (upper part of Table 2). In all four countries, TFP has increased significantly at an annual rate varying from $2.4 \%$ for Sweden to $3.1 \%$ for Finland. Although, overall, Finland displays the fastest growth, further analysis indicates that differences among the four countries are small and vary from year to year. Thus, we conclude that TFP growth has been roughly comparable in the four countries considered here. Table 2 further shows that productivity growth in the four countries, although of a similar magnitude, has been achieved through different channels. Output per farm has expanded in all four countries, but the annual growth rate for Denmark (10.4\%) stands out as particularly high (the corresponding rate for Finland is only 6.4\%). The input side section of Table 2 reveals that a large share of the growth in output has been achieved by increasing the quantities of production factors, at an annual rate varying from $3.1 \%$ for Germany to $7.2 \%$ for Denmark. The countries with the highest output growth rates are also those with the highest input growth rates and there is therefore no "miracle growth". In all countries, other inputs are substituted for labour, but the relative contributions of feeds and capital to input growth vary. For instance, the contribution of capital investments to input growth is much larger in Finland than in Sweden, where the increase in feeds has played a quantitatively larger role. Denmark stands out by the importance of capital to input growth, which reflects the high level of investment by Danish dairy farms over the last two decades.

The growth accounting results including the four new entrants over the shorter period 2004-2010 (lower part of Table 2) indicate that the situation for those countries is not very stable, with important year-to-year variations. The shock of entry into the EU was followed by a decline in productivity, which stopped between 2006 and 2008, followed by some productivity growth, but TFP actually decreased again in three countries in year 2010. The frustratingly short time series make it difficult to infer long-term trends. Finland, over the shorter 2004-2010 period, enjoyed the second highest TFP growth rate, with farm productivity growing faster only in Denmark. TFP growth was significantly larger in Finland than in the four newer EU members, and there is therefore no evidence that those countries are catching up in terms of TFP. Hence, for Estonia, TFP growth does not match growth in labour productivity, suggesting that capital and feeds have substituted labour with limited efficiency gains. Overall, productivity growth does not seem to be slowing down in Finland, unlike in Sweden and Germany.

TFP levels have also been compared using Data Envelopment Analysis (DEA) and the 2004 Farm Accountancy Data Network (FADN) subsample of Finnish dairy farms to construct the efficiency frontier against which to benchmark each country. Although tentative, that analysis indicates that, as expected, Denmark is the clear productivity leader. Among the old EU members, Finland has the least efficient dairy farms, although the cross-country productivity differences are not as large as suggested by analysis of labour productivity differences. This confirms that Finland suffers from a productivity deficit with respect to not only Denmark but also the old EU members of the Baltic Sea region (Sweden and Germany). More surprisingly, the analysis indicates that farm productivity levels were comparable in Finland and several new EU entrants (Latvia, Lithuania, Poland) in year 2004. Estonia achieved the lowest level of productivity, but this was before the TFP growth documented subsequently. 
Table 3 reports the levels of labour productivity in the dairy processing sector of the eight countries from 1995 to 2010, using as indicator the deflated value of output per worker. The four new entrants exhibit relatively low levels of productivity compared to the older EU members, but have also experienced relatively fast productivity growth. For instance, the productivity of workers in the Lithuanian dairy processing sector grew at the impressive annual rate of 10\% from 2000 to 2010, but this growth was achieved from an initially low level: in year 2000, a worker in Lithuania was producing 13 times less than an equivalent worker in Germany. Hence, a process of convergence in labour productivity in dairy processing has started, with the relative "laggards" growing faster than the relative leaders. As a result, in year 2010, the ratio of the highest level of labour productivity, for Germany, to the lowest one, for Latvia, had shrunk to seven. This also means that cross-country differences in labour productivity, while still large, are now smaller in the dairy processing sector than in primary production.

On the basis of the labour productivity indicator, the Finnish dairy processing sector appears to be competitive. Although output per worker is significantly smaller in Finland than in Germany, the difference in fact disappears when expressing labour productivity in terms of value-added (rather than output) per worker. Focusing on the four older EU members, it is evident that growth in labour productivity has been much faster on farms than in the processing sectors. In the case of Finland, for instance, labour productivity grew 6.9\% a year on average in primary production over the 1995-2010 period (Table 1), while the corresponding figure is only $1.3 \%$ in the processing sector (Table 3 ). The same pattern is visible in the three old EU countries, with Sweden standing out by the quasi absence of labour productivity growth in its processing sector. Hence, most of the productivity growth in the dairy chains of the old EU members has been achieved on farms, while this is not necessarily the case for the four relatively newer EU members.

The results of the growth accounting exercise for dairy processing are presented in Table 4. Unfortunately, only seven countries are represented in the table because the required data for Denmark was simply not available. The results are roughly consistent with those established on the basis of the labour productivity indicator. First, the performance of the Finnish dairy processors in terms of TFP growth appears satisfactory when compared to that of processors in the old EU member countries. TFP in Finnish dairy processing grew at only $0.32 \%$ annually over the full study period, but this rate appears satisfactory in relative terms given that TFP actually decreased slightly in Germany and Sweden over the same period of time. In Finland, output of the dairy processing sector has been almost stagnant, but productivity has increased due to a slow and steady reduction in inputs - mainly labour and materials. When we extend the comparison to include the four new EU members, the results of the growth accounting exercise confirm the conclusion reached on the basis of the labour productivity indicator: productivity growth in the newer EU members is occurring at a faster rate than in the older EU members, so that the former are steadily catching up with the latter in terms of TFP. However, the situation is not homogenous: the dairy processing sectors of Poland and Lithuania have experienced much faster productivity growth than those of Latvia and Estonia. In the case of Poland, output growth $(5.12 \%$ annually) has outstripped input growth (1.40\% annually) by a large margin, hence suggesting that the sector has been particularly successful in adding value to the raw material that it processes. We note that output has also grown quickly in the two countries performing best, supporting the idea that productivity growth is more easily achieved in the dairy sectors that are expanding rather than shrinking.

\section{Conclusions}

This analysis reveals that the Finnish dairy supply chain continues to suffer from a relative lack of competitiveness when compared to the dairy sectors of the old EU members of the Baltic Sea area. At farm level, large investments, innovations and structural changes have generated fast growth in productivity, but Denmark, Sweden, and Germany followed similar trends so that the relative position of Finnish farms has not changed much over 15 years. A key constraint on the level of labour productivity in Finland remains the relatively high labour requirements per dairy cow, which reflect the relatively small size of farms. Looking forward, however, this situation means that further farm concentration in Finland will generate large productivity gains, while structural change is likely to 
slow down in other countries such as Denmark. Another positive element is the finding that in recent years (i.e., since 2004), TFP on Finnish farms has also grown much faster than on German and Swedish farms. Altogether, Finnish farms appear in the process of raising their productivity to the level achieved by German and Swedish farms, while Danish farms are on a league of their own. Extending the comparison to include the new EU members reveals that dairy farms in those countries are lagging behind Finnish ones in terms of productivity and are not catching up. Although Estonian farms, which are on average relatively large, have recorded impressive increases in yields and labour productivity, this has been achieved more by substitutions of other production factors for labour rather than real efficiency gains.

The processing level of the Finnish dairy supply chain appears more competitive when benchmarked against the processing sectors of the old EU members, although TFP growth has been slow in absolute terms. However, our analysis also indicates that productivity of the dairy manufacturing industries of Poland and Lithuania is increasing rapidly. Overall, the evolution documented in the paper is consistent with the view that transferring technologies and organisational forms from the productivity leaders to the productivity "laggards" is easier in the manufacturing sector than in primary production, due to the typical difference in the size of farms as well as the more pronounced reliance of the primary sector on country-specific agro-ecological conditions.

Table 1: Partial productivity of dairy farms

\begin{tabular}{|c|c|c|c|c|c|c|c|c|}
\hline & Germany & Denmark & Sweden & Finland & Estonia & Latvia & Lithuania & Poland \\
\hline \multicolumn{9}{|l|}{ Yield } \\
\hline \multicolumn{9}{|c|}{ Level (kg of milk/dairy cow) } \\
\hline 1995 & 5538 & 6392 & 7630 & 6865 & & & & \\
\hline 2004 & 6747 & 7900 & 7955 & 8165 & 5653 & 4629 & 4476 & 4682 \\
\hline 2010 & 7493 & 8537 & 8329 & 8592 & 7318 & 5450 & 5213 & 5056 \\
\hline \multicolumn{9}{|l|}{ Annual Growth } \\
\hline $1995-2010$ & $2.0 \%$ & $1.9 \%$ & $0.6 \%$ & $1.5 \%$ & & & & \\
\hline $2004-2010$ & $1.8 \%$ & $1.3 \%$ & $0.8 \%$ & $0.9 \%$ & $4.4 \%$ & $2.8 \%$ & $2.6 \%$ & $1.3 \%$ \\
\hline \multicolumn{9}{|c|}{ Labour requirements } \\
\hline \multicolumn{9}{|c|}{ Level (hours/dairy cow) } \\
\hline 1995 & 127 & 69 & 140 & 321 & & & & \\
\hline 2004 & 93 & 46 & 111 & 222 & 258 & 341 & 404 & 319 \\
\hline 2010 & 83 & 33 & 85 & 148 & 163 & 264 & 340 & 290 \\
\hline \multicolumn{9}{|l|}{ Annual Growth } \\
\hline $1995-2010$ & $-2.8 \%$ & $-4.7 \%$ & $-3.3 \%$ & $-5.0 \%$ & & & & \\
\hline 2004-2010 & $-1.8 \%$ & $-5.3 \%$ & $-4.4 \%$ & $-6.5 \%$ & $-7.3 \%$ & $-4.2 \%$ & $-2.8 \%$ & $-1.6 \%$ \\
\hline \multicolumn{9}{|l|}{ Labour Productivity } \\
\hline \multicolumn{9}{|c|}{ Level (kg of milk/hour) } \\
\hline 1995 & 44 & 92 & 55 & 21 & & & & \\
\hline 2004 & 73 & 170 & 72 & 37 & 22 & 14 & 11 & 15 \\
\hline 2010 & 90 & 255 & 98 & 58 & 45 & 21 & 15 & 17 \\
\hline \multicolumn{9}{|l|}{ Annual Growth } \\
\hline $1995-2010$ & $5.0 \%$ & $7.0 \%$ & $4.0 \%$ & $6.9 \%$ & & & & \\
\hline 2004-2010 & $3.7 \%$ & $7.0 \%$ & $5.4 \%$ & $7.9 \%$ & $12.6 \%$ & $7.2 \%$ & $5.6 \%$ & $2.9 \%$ \\
\hline
\end{tabular}

Table 2: Growth accounting and TFP growth for milk farms

\begin{tabular}{ccccccccccccc}
\hline Period & Country & \multicolumn{3}{c}{ Annual output growth (\%) } & \multicolumn{3}{c}{ Annual Input growth (\%) } & \multicolumn{3}{c}{ TFP growth } \\
& & TOTAL & Milk & Crop & Livestock & TOTAL & Feeds & Capital & Labour & Other & (\%) \\
\hline $\mathbf{1 9 9 5 - 2 0 1 0 ~ F i n l a n d ~}$ & $\mathbf{6 . 4}$ & $\mathbf{5 . 6}$ & $\mathbf{0 . 5}$ & $\mathbf{0 . 3}$ & $\mathbf{3 . 2}$ & $\mathbf{1 . 1}$ & $\mathbf{1 . 8}$ & $-\mathbf{0 . 1}$ & $\mathbf{0 . 3}$ & $\mathbf{3 . 1}$ \\
Sweden & $\mathbf{7 . 4}$ & 4.8 & 1.9 & 0.6 & $\mathbf{4 . 9}$ & 2.2 & 1.3 & 0.9 & 0.4 & $\mathbf{2 . 4}$ \\
Germany & $\mathbf{5 . 6}$ & 4.4 & 0.8 & 0.4 & $\mathbf{3 . 1}$ & 1.0 & 1.1 & 0.2 & 0.7 & $\mathbf{2 . 4}$ \\
Denmark & $\mathbf{1 0 . 4}$ & 7.3 & 2.4 & 0.5 & $\mathbf{7 . 2}$ & 2.9 & 3.1 & 0.5 & 0.4 & $\mathbf{3 . 0}$ \\
\hline $\mathbf{2 0 0 4 - 2 0 1 0}$ Finland & $\mathbf{6 . 7}$ & $\mathbf{5 . 9}$ & $\mathbf{0 . 6}$ & $\mathbf{0 . 1}$ & $\mathbf{2 . 6}$ & $\mathbf{1 . 1}$ & $\mathbf{1 . 3}$ & $\mathbf{- 0 . 4}$ & $\mathbf{0 . 5}$ & $\mathbf{4 . 1}$ \\
Sweden & $\mathbf{4 . 5}$ & 4.4 & 0.0 & 0.1 & $\mathbf{3 . 2}$ & 1.4 & 1.1 & 0.5 & 0.2 & $\mathbf{1 . 3}$ \\
Germany & $\mathbf{5 . 7}$ & 4.0 & 1.2 & 0.4 & $\mathbf{4 . 0}$ & 1.6 & 0.8 & 0.5 & 1.1 & $\mathbf{1 . 6}$ \\
Denmark & $\mathbf{1 3 . 7}$ & $\mathbf{7 . 1}$ & 5.5 & 0.6 & $\mathbf{7 . 9}$ & 5.1 & 1.7 & 0.5 & 0.5 & $\mathbf{5 . 8}$ \\
Poland & $\mathbf{3 . 8}$ & 2.5 & 0.3 & 1.0 & $\mathbf{3 . 5}$ & 1.1 & 1.8 & 0.2 & 0.4 & $\mathbf{0 . 3}$ \\
Estonia & $\mathbf{6 . 1}$ & 4.5 & 1.2 & 0.4 & $\mathbf{3 . 6}$ & 2.7 & 1.6 & -1.1 & 0.4 & $\mathbf{2 . 5}$ \\
Latvia & $\mathbf{0 . 8}$ & 2.6 & -1.4 & -0.4 & $\mathbf{- 1 . 0}$ & 0.1 & 0.3 & -0.8 & -0.6 & $\mathbf{1 . 8}$ \\
Lihthuania & $\mathbf{7 . 3}$ & 4.1 & 1.7 & 1.4 & $\mathbf{7 . 7}$ & 1.0 & 5.9 & 0.5 & 0.1 & $\mathbf{- 0 . 3}$ \\
\hline
\end{tabular}


Table 3: Labour productivity in dairy manufacturing (€1000s of output per worker, at year 2010 price level)

\begin{tabular}{lcccccccc}
\hline \multicolumn{7}{c}{ Country } \\
Year & Denmark & Germany & Estonia & Latvia & Lithuania & Poland & Finland & Sweden \\
\hline 1995 & 423 & - & - & - & - & - & 344 & 334 \\
1996 & 431 & - & - & - & - & - & 342 & 353 \\
1997 & 413 & - & - & - & - & - & 342 & 328 \\
1998 & 429 & - & - & - & - & - & 324 & 316 \\
1999 & 438 & 548 & - & 46 & - & - & 349 & 341 \\
2000 & 318 & 559 & 85 & 54 & 41 & - & 389 & 371 \\
2001 & 335 & 584 & 107 & 61 & 47 & - & 407 & 334 \\
2002 & 334 & 581 & 109 & 66 & 52 & 81 & 419 & 220 \\
$\ldots$, & $\ldots$ & $\ldots$ & $\ldots$ & $\ldots$ & $\ldots$ & $\ldots$ & $\ldots$ & $\ldots$ \\
2010 & 542 & 662 & 156 & 95 & 106 & 148 & 417 & 341 \\
Average growth rate of labour productivity & & & & \\
Period & $1995-20101999-2010$ & $2000-10$ & $1999-2010$ & $2000-10$ & $2002-10$ & $1995-20101995-2010$ \\
Value & $1.7 \%$ & $1.7 \%$ & $6.3 \%$ & $6.9 \%$ & $10.0 \%$ & $7.7 \%$ & $1.3 \%$ & $0.1 \%$ \\
\hline
\end{tabular}

Table 4: Growth accounting in dairy processing

\begin{tabular}{|c|c|c|c|c|c|c|c|}
\hline \multirow[t]{2}{*}{ Period } & \multirow[t]{2}{*}{ Country } & \multirow{2}{*}{$\begin{array}{c}\text { Annual output growth (\%) } \\
\text { TOTAL }\end{array}$} & \multicolumn{4}{|c|}{ Annual Input growth (\%) } & \multirow{2}{*}{$\begin{array}{l}\text { TFP } \\
\text { growth }\end{array}$} \\
\hline & & & TOTAL & Materials & Labour & Capital & \\
\hline \multirow[t]{3}{*}{ 1995-2011 } & Finland & $-0.11 \%$ & $-0.43 \%$ & $-0.30 \%$ & $-0.13 \%$ & $0.00 \%$ & $0.32 \%$ \\
\hline & Sweden & $-1.17 \%$ & $-0.71 \%$ & $-0.27 \%$ & $-0.45 \%$ & $0.01 \%$ & $-0.46 \%$ \\
\hline & Germany & $0.37 \%$ & $0.62 \%$ & $0.82 \%$ & $-0.16 \%$ & $-0.04 \%$ & $-0.25 \%$ \\
\hline \multirow[t]{8}{*}{$2000-2011$} & Finland & $0.53 \%$ & $-0.20 \%$ & $-0.21 \%$ & $0.00 \%$ & $0.01 \%$ & $0.73 \%$ \\
\hline & Sweden & $-1.41 \%$ & $-1.30 \%$ & $-0.82 \%$ & $-0.49 \%$ & $0.01 \%$ & $-0.11 \%$ \\
\hline & Germany & $0.51 \%$ & $1.09 \%$ & $1.18 \%$ & $-0.06 \%$ & $-0.03 \%$ & $-0.57 \%$ \\
\hline & Denmark & $1.48 \%$ & .. & .. & .. & .. & .. \\
\hline & Poland & $5.12 \%$ & $1.40 \%$ & $1.60 \%$ & $-0.26 \%$ & $0.06 \%$ & $3.66 \%$ \\
\hline & Lithuania & $5.29 \%$ & $2.83 \%$ & $3.19 \%$ & $-0.36 \%$ & $0.01 \%$ & $2.39 \%$ \\
\hline & Latvia & $1.89 \%$ & $0.39 \%$ & $0.79 \%$ & $-0.46 \%$ & $0.06 \%$ & $1.49 \%$ \\
\hline & Estonia & $-0.68 \%$ & $-0.96 \%$ & $-0.78 \%$ & $-0.28 \%$ & $0.10 \%$ & $0.28 \%$ \\
\hline
\end{tabular}

\section{References}

Aiginger, K. 2006. Revisiting an evasive concept: introduction to the special issue on competitiveness. Journal of Industrial Competition \& Trade 6: 63-66.

Coelli, T., Rao, D. S. P. \& Battese, G. E. 1998. An introduction to efficiency and productivity analysis, Kluwer Academic Publishing, Boston.

DEFRA 2002. Development of competitiveness indicators for the food chain industries, DEFRA Working Paper, Economics (international) Division.

Gopinath, M, \& Roe T. L. 1997. Sources of sectoral growth in an economy wide context: the case of U.S. agriculture, Journal of Productivity Analysis 8: 293-310.

Hayami, H. \& Ruttan, V. 1991. Agricultural Development - An International Perspective, The John Hopkins University Press, Baltimore, USA.

Irz, X. \& Kuosmanen, N. forthcoming 2013. Explaining growth in demand for dairy products in Finland: An econometric analysis. Food Economics.

Latruffe, L. 2010. Competitiveness, Productivity and efficiency in the agricultural and agri-food sectors, OECD Food, Agriculture and Fisheries Working Papers, No 30, OECD Publishing.

Lelyon, B., Chatellier, V., \& Daniel, K. 2011. Phasing out milk quotas: a bio-economic model to analyse the impacts on French dairy farms. Chapter 25 (pp. 393-417) in Sorrentino, A., Henke, R., Severini, S. (edts), The CAP after the Fischler reform, Ashgate, Farnham, UK.

Niemi, J. \& Alhstedt, J. (eds) 2013. Finnish agriculture and rural industries 2013, vol. 113a. MTT Agrifood Research Finland, Helsinki.

Rikkonen, P. 2005. Scenarios for future agriculture in Finland: a Delphi study among agri-food sector stakeholders. Agriculture and Food Science 14(3): 205-223. 